MATEC Web of Conferences 22,05019 (2015)

DOI: $10.1051 /$ matecconf/ 20152205019

(C) Owned by the authors, published by EDP Sciences, 2015

\title{
Study on Preparation and Physical Mechanical Properties of $\mathrm{Si}_{3} \mathrm{~N}_{4}$ Composite Ceramics
}

\author{
Wei Chen, Zhenglin Lv*, Dongqiang Gao \& Xu Ai \\ College of Mechanical and Electrical Engineering, Shaanxi University of Science \& Technology, Xi'an, Shaanxi, \\ China
}

\begin{abstract}
In this paper, by using the hot-pressed sintered technology, pure $\mathrm{Si}_{3} \mathrm{~N}_{4}$ ceramics and $\mathrm{Si}_{3} \mathrm{~N}_{4}$ composite ceramics containing different volume fraction $(\mathrm{hBN})$ are prepared with the sintered catalyst of $\mathrm{Al}_{2} \mathrm{O}_{3}$ and $\mathrm{Y}_{2} \mathrm{O}_{3}$ (total 10vol\%) by HIGH MULTI 5000 multi-functional high temperature sintering furnace. And the phase compositions, microstructure and mechanical properties of specimen were studied. The results show that, based on the hot pressing sintering process, the $\alpha-\mathrm{Si}_{3} \mathrm{~N}_{4}$ is all changed into $\beta-\mathrm{Si}_{3} \mathrm{~N}_{4}$. Addition of $h B N$ into $\mathrm{Si}_{3} \mathrm{~N}_{4}$ inhibits the growth of the crystal grain and makes the ceramic materials generate $\mathrm{hBN}$ segregation zone in internal materials, which causes the addition of hBN that cannot improve the physical mechanical properties effectively just because the serious stress concentrates and fatigue break down. In addition, compared with other sintering process, the physical and mechanical properties of $\mathrm{Si}_{3} \mathrm{~N}_{4}$ prepared by hot-pressing sintering are better than other methods. Improvement of sintering temperature and time can refine the crystal grain and be a helpful densification. The changed $\beta-\mathrm{Si}_{3} \mathrm{~N}_{4}$ grain completely forms an intertwined structure and increases the physical and mechanical properties of $\mathrm{Si}_{3} \mathrm{~N}_{4}$. Meanwhile, $\mathrm{Y}_{2} \mathrm{O}_{3}$ and $\mathrm{Al}_{2} \mathrm{O}_{3}$ additives are melted and filled into Si3N4 particles at the high temperature, leading to a significant drop of the porosity and the increase of density.
\end{abstract}

Keywords: $\mathrm{Si}_{3} \mathrm{~N}_{4}$ Composite Ceramics; hot pressed sintering; Physical Mechanical Properties

\section{INTRODUCTION}

$\mathrm{Si}_{3} \mathrm{~N}_{4}$ ceramic occupies an important position in engineering ceramic, because it has excellent comprehensive performances such as high strength, high temperature resistance, oxidation resistance, wear resistance, heat shock resistance and so on. Thus it is widely used in mechanical, chemical, oceanographic engineering, aerospace and other important areas. But pure $\mathrm{Si}_{3} \mathrm{~N}_{4}$ ceramic material is limited in engineering because it's very fragile and rigid. In order to improve the physical and mechanical properties of $\mathrm{Si}_{3} \mathrm{~N}_{4}$ ceramic, some scholars adopt additive with stratified structure ${ }^{[1]}$. By deflection of the crack and bridging of the layer, the main crack growth resistance will increase greatly, and the fracture toughness property and flaw tolerance will be greatly increase, too. In this regard, Saito $\mathrm{T}$ et a $1^{[2]}$ and Liu $\mathrm{H}$ et $\mathrm{al}^{[3]}$ adopt $\mathrm{BN}$ as an additive of ceramic material and product $\mathrm{Si}_{3} \mathrm{~N}_{4}$ ceramics matrix layered composites which shows perfect fracture toughness.

Sintering as the end process of ceramic material production which has great influence on the ultimate performance of ceramic material ${ }^{[4]}$. Therefore, it's important to select the sintering method and control the sintering process strictly. The way to sinter ceramic material can be generally divided into: general sintering, reaction sintering, atmosphere pressure sintering, heat-pressing sintering, heat isostatic pressing sintering, microwave sintering, the discharge plasma sintering and high temperature self-propagating sin-

*Corresponding author: 649192844@,qq.com tering. For polycrystalline materials, the grain boundary condition plays an important role in mechanical properties. $\mathrm{Si}_{3} \mathrm{~N}_{4}$ is high covalent compound because its covalent bond accounts for 70 percentage and the electrovalent bond accounts for 30 percentage. The self-diffusion coefficient of nitrogen-atoms and silicon-atoms is small; the volume diffusion, the grain boundary diffusion velocity, and the sintering driving force of densification are small; only the sintering temperature which is close to $\mathrm{Si}_{3} \mathrm{~N}_{4}$ dispersion temperature $\left(>1850{ }^{\circ} \mathrm{C}\right)$ and atomic migration have enough speed. It shows that the heat-pressing sintering is a good method to densifying the ceramic ${ }^{[5-8]}$.

In this paper, the $\mathrm{Si}_{3} \mathrm{~N}_{4}-\mathrm{hBN}$ composite ceramic material ( $\mathrm{hBN}$ content gradient change) is obtained by heat-pressing sintering which are added $\mathrm{Al}_{2} \mathrm{O}_{3}$ and $\mathrm{Y}_{2} \mathrm{O}_{3}$ as sintering catalysts and $\mathrm{Si}_{3} \mathrm{~N}_{4}$ powder and hexagonal boron nitride powder as raw materials. What's more, the rule of corresponding layered composite materials mechanics performance which is compared with other sintering methods is investigated.

\section{EXPERIMENT}

\subsection{Preparation}

Pure $\mathrm{Si}_{3} \mathrm{~N}_{4}$ and $\mathrm{Si}_{3} \mathrm{~N}_{4}$-hBN ceramic composite is obtained in HIGH MULTI 5000 Multi-functional high-temperature sintering furnace which is added Si3N4 powder (purity is $99.99 \%$, phase alpha $>94 \%$, 
the average particle size is 0.3 microns) and $\mathrm{hBN}$ powder (purity is $99.6 \%$, the average particle size is 0.5 microns) as raw materials, $\mathrm{Al}_{2} \mathrm{O}_{3}$ and $\mathrm{Y}_{2} \mathrm{O}_{3}$ powder (purity $99.5 \%$, the average particle size is $1 \mathrm{mi}-$ crons) as sintering catalyst. The $\mathrm{hBN}$ content in Si3N4-hBN ceramic composite is 5vol.\%, 10vol.\%,20vol.\% and 30vol.\%. Sintered samples are disc samples, the size is $\Phi 44 \mathrm{~mm} * 6 \mathrm{~mm}$.

The heat-pressing sintering process of Si3N4-hBN ceramic composite material is divided into the following seven steps: (1) Burdening: Weighing the Si3N4, $\mathrm{hBN}, \mathrm{Y}_{2} \mathrm{O}_{3}$ and $\mathrm{Al}_{2} \mathrm{O}_{3}$ powder ingredients in certain proportion by using electronic balance. (2) Ball mill mixing: Put the powder in the ball mill jar and add alcohol (in which the quantity is about $1 / 2$ ), adjust the fluid viscosity by using the planetary ball mill at the rate of $150 \mathrm{r} \cdot$ min-1until $5 \mathrm{~h}$. (3) Drying: Dry the powder in the oven, stir the powder until the alcohol is lost, however, prevent the powder from changing into block. (4)Selecting: Grind the mixture and select by 160-mesh sieve. (5)Loading: Mat the graphite paper whose thickness is $0.2 \mathrm{~mm}$ around the mould in order to demould easily, and preload the powder in the mould. Figure 1 shows the structure diagram of the mould. (6)Heat-pressing: Put the mould loaded powder in the HIGH MULTI 5000 multi-function sintering furnace, sintering after well installed, and the heat-pressing sintering process is using nitrogen atmosphere to protect it. The temperature is $1800^{\circ} \mathrm{C}$, the pressure is 30MPA, and the thermal pressure maintaining time is $30 \mathrm{~min}$. (7) Demould: Open the furnace lid until the furnace temperature reaches to room temperature, take out the mould, and take out the sintered sample from the mould, tear off the graphite paper from the sample.

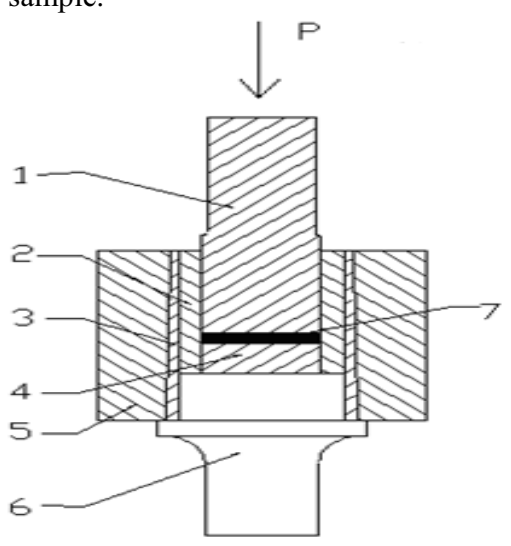

Figure 1. Graphite Mould

1 is the Upper Die; 2 is the Internal Shell; 3 is the Mid Sleeve; 4 is the Lower Die; 5 is the Out Sleeve; 6 is the Substrate

The plate was grinded into $5 \mathrm{~mm} \times 5 \mathrm{~mm} \times 20 \mathrm{~mm}$ as mechanics performance test sample by inner circle cutting machine. The ceramic phase was analyzed by
X-ray diffraction machine. The fracture morphology was examined by scanning electron microscope.

\subsection{Physical and mechanical performance test methods}

For heat-pressing sintered sample, the density and open porosity are measured by Archimedes principle method; the hardness is measured by Vickers; the bending strength is measured by three point bending test; the fracture toughness is measured by indentation method; the detailed test method is shown as follows:

(1)Density and open porosity

The density and open porosity of the heat-pressing sintered $\mathrm{Si}_{3} \mathrm{~N}_{4}-\mathrm{hBN}$ sample are measured by Archimedes principle method.

When measure the density and open porosity, first, clean the sample surface; second, boil the sample in distilled water for 1 hour until gas out of sample; third, measure the mass of sample in water, the mass of wet sample and drying mass of the sample in pheatoelectric analytical balance (sensitivity of 1/10000). Calculate the sample density and open porosity according to the formula (1), (2) ${ }^{[9]}$.The density calculation formula is shown as follows:

$d_{\text {sample }}=\frac{m_{d r y}}{V_{\text {displacement }}}=\frac{m_{d r y} d_{\text {water }}}{m_{\text {wet }}-m_{\text {water }}}$

In the formula: $d_{\text {sample }}$ is the density of the sample $/ \mathrm{g} \cdot \mathrm{cm}^{-3}$;

$m_{d r y}$ is the drying mass of sample /g;

$v_{\text {displacement }}$ is the displacement of the sample in water;

$m_{\text {water }}$ is the mass of the sample in water;

$m_{\text {wet }}$ is the mass of the wet sample/g;

$d_{\text {water }}$ is the density of water $/ \mathrm{g} \cdot \mathrm{cm}-3$. Open porosity calculation formula is shown as follows:

$P=\frac{m_{\text {wet }}-m_{d r y}}{m_{\text {wet }}-m_{\text {water }}} \times 100 \%$

In this formula: $\mathrm{P}$ is the open porosity of the sample $/ \%$.

(2)Bending strength

The bending strength of the heat-pressing sintered $\mathrm{Si}_{3} \mathrm{~N}_{4}$-hBN ceramic composite material can be measured by three point bending test in the electronic universal material testing machine. The sample span is $16 \mathrm{~mm}$, the loading speed is $0.5 \mathrm{~mm} \cdot \mathrm{min}^{-1}$, and take the average of five samples. The calculating formula of bending strength is shown in formula (3) ${ }^{[9]}$ :

$\sigma_{w}=\frac{3 P L}{2 b h^{2}}$

In this formula: $\sigma_{w}$ is the bending strength/MPa; $\mathrm{L}$ is the fulcrum span/mm;P is the breaking load $/ \mathrm{N}$; b 
is the width of bar sample/mm; $h$ is the height of bar sample/mm.

(3) Vickers hardness

Polish the sample on mirror, the hardness can be measured in Hv Vickers. Using the diamond indenter of $136^{\circ}$ apex Angle, and the load is $5 \mathrm{~kg}$. Taking at least five areas of each sample, the average of the two diagonals is taken in each area, and the error of two diagonals is not greater than $10 \%$.Calculation formula as shown in formula $(4)^{[10]}$ :

$$
H_{v}=1.8544 \frac{p}{d^{2}}
$$

In this formula: $H_{v}$ is the Vickers hardness/GPa; $P$ is the load $/ \mathrm{N} ; d$ is the diagonal length $/ \mu \mathrm{m}$.

(4) Fracture toughness

The fracture toughness can be calculated by measuring the diagonal crack length through using indentation method, the calculation formula is shown in $(5)^{[10]}$ as follows:

$$
K_{\text {IC }}=0.075 P c^{-1.5}
$$

In the formula: $K_{I C}$ is the fracture toughness/MPa $\bullet \mathrm{m} 1 / 2 ; P$ is the load $/ \mathrm{N} ; c$ - is the half length of $\mathrm{crack} / \mu \mathrm{m}$.

\section{RESULTS AND DISCUSSION}

\subsection{Phase composition}

The phase composition of heat-pressing sinter sample is analyzed by XRD. The diffraction pattern is shown in Figure 2. It's easy to see that $\alpha-\mathrm{Si}_{3} \mathrm{~N}_{4}$ is translated into $\beta-\mathrm{Si}_{3} \mathrm{~N}_{4}$ after heat-pressing sintering. Due to the $\alpha-\mathrm{Si}_{3} \mathrm{~N}_{4}$ is graininess and $\beta-\mathrm{Si}_{3} \mathrm{~N}_{4}$ is rod-like, the symmetry of $\beta-\mathrm{Si}_{3} \mathrm{~N}_{4}$ phase is higher than $\alpha$ phase in two types of crystal. At the same time, the mismatch displacement between the $\alpha-\mathrm{Si}_{3} \mathrm{~N}_{4}$ layer changes the length of Si-N bond. The $\alpha-\mathrm{Si}_{3} \mathrm{~N}_{4}$ tetrahedron crystal structure is easy to tilt and distort. The interlayer displacement will cause the lattice distortion, and $\alpha$ phase will have higher entropy. As a result, the $\beta-\mathrm{Si}_{3} \mathrm{~N}_{4}$ has higher thermal stability than $\alpha-\mathrm{Si}_{3} \mathrm{~N}_{4}$ phase.

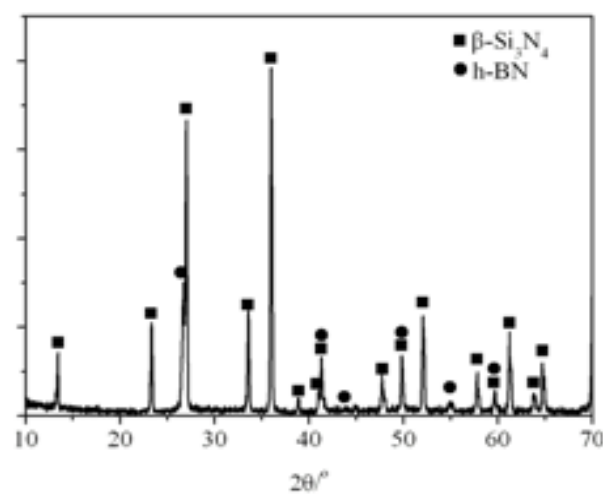

Figure 2. 2 XRD spectra of heat-pressing sintering $\mathrm{Si}_{3} \mathrm{~N}_{4}-20 \%$ hBN sample

Structure of $\mathrm{Si}_{3} \mathrm{~N}_{4}-20 \%$ hBN sample is shown in Figure 3, Figure "1" is a rod-like $\beta-\mathrm{Si}_{3} \mathrm{~N}_{4}$, and Figure "2" is the flake layer hBN. The "1" and "2" point are analyzed by EDS in Figure 3. The results are shown in Table 1 , the Si content in"1" area is significantly higher than "2" area, and the content B in "2" area is significantly higher than "1" area, which further confirmed that the "1" area is $\mathrm{Si}_{3} \mathrm{~N}_{4}$ area, "2" $\mathrm{Si}_{3} \mathrm{~N}_{4}$ is $\mathrm{hBN}$ area.

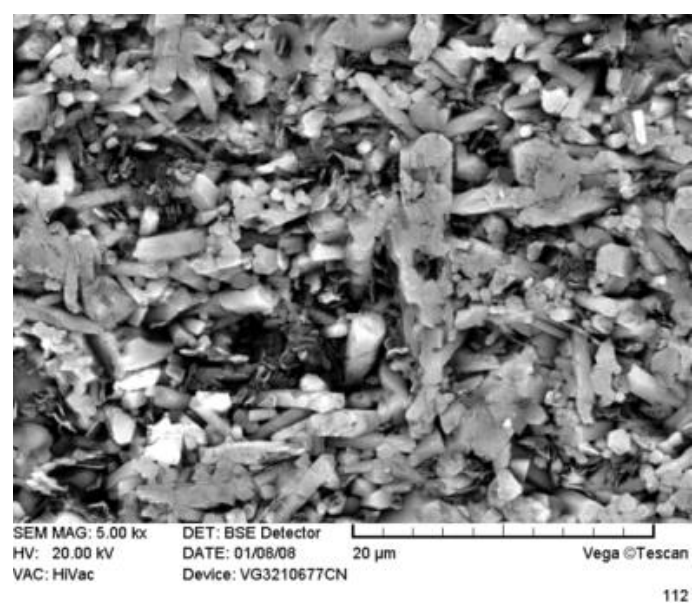

Figure 3. Corrosion surface topography of heat-pressing sintering $\mathrm{Si}_{3} \mathrm{~N}_{4}-20 \% \mathrm{hBN}$ (SEM)

Table 1. Energy spectrum analysis of surface composition in $\mathrm{Si}_{3} \mathrm{~N}_{4}-20 \%$ hBN sample (EDS)

\begin{tabular}{lll}
\hline & 1region Atomic\% & 2region Atomic\% \\
\hline B K & - & 47.66 \\
N K & 59.91 & 43.55 \\
O K & 6.76 & 4.32 \\
Si K & 31.6 & 4.01 \\
Al K & 1.72 & - \\
Y K & - & 0.46 \\
\hline
\end{tabular}

\subsection{Microstructure}

Observing the morphology of fracture in $\mathrm{Si}_{3} \mathrm{~N}_{4}-\mathrm{hBN}$ ceramic composite which volume fraction of $\mathrm{hBN}$ were $0 \%, 10 \%, 20 \%$ and $30 \%$, as shown in Figure 4 (a), (b), (c) and (d), $\mathrm{Si}_{3} \mathrm{~N}_{4}$ grain size become smaller as the increase of the content of hBN. At the same time, the fracture morphology of $\mathrm{Si}_{3} \mathrm{~N}_{4}$ gradually translates from mainly transgranular fracture morphology (flat fracture) to main intergranular fracture morphology (pit). It can be clearly observed that the pits when grain comes out from fracture morphology of $\mathrm{Si}_{3} \mathrm{~N}_{4}-30 \%$ hBN ceramic composite (Figure $4 \mathrm{~d}$ ). Indicate that as 
MATEC Web of Conferences

Table 2. Physical properties of heat-pressing sintering $\mathrm{Si}_{3} \mathrm{~N}_{4}$ and $\mathrm{Si}_{3} \mathrm{~N}_{4}-\mathrm{hBN}$ sample

\begin{tabular}{lclll}
\hline Sample No. & $\begin{array}{l}\text { hBN Content } \\
/ \text { vol. } \%\end{array}$ & $\begin{array}{l}\text { Density } \\
/ \mathrm{g} \cdot \mathrm{cm}^{-3}\end{array}$ & $\begin{array}{l}\text { Vickers Hardness } \\
/ \mathrm{GPa}\end{array}$ & $\begin{array}{l}\text { Porosity } \\
/ \%\end{array}$ \\
\hline SN0 & 0 & 3.31 & 19.9 & 0.84 \\
SN5 & 5 & 3.17 & 19.6 & 0.90 \\
SN10 & 10 & 3.10 & 15.3 & 0.91 \\
SN20 & 20 & 2.97 & 9.3 & 1.04 \\
SN30 & 30 & 2.94 & 6.7 & 1.05 \\
\hline
\end{tabular}

Table 3. Mechanics performance of $\mathrm{Si}_{3} \mathrm{~N}_{4}$ ceramics made by different sintering by contrast

\begin{tabular}{|c|c|c|c|c|}
\hline Material type & $\begin{array}{l}\text { Heat-pressing sinter- } \\
\text { ing } \mathrm{Si}_{3} \mathrm{~N}_{4}\end{array}$ & $\begin{array}{l}\text { Reaction sintering } \\
\mathrm{Si}_{3} \mathrm{~N}_{4}\end{array}$ & $\begin{array}{l}\text { Pressureless sintering } \\
\mathrm{Si}_{3} \mathrm{~N}_{4}\end{array}$ & $\begin{array}{l}\text { Post-sintering } \\
\mathrm{Si}_{3} \mathrm{~N}_{4}\end{array}$ \\
\hline Density $/ \mathrm{g} \cdot \mathrm{cm}^{3}$ & $3.2-3.4$ & $2.7-2.8$ & $3.2-3.26$ & $3.2-3.3$ \\
\hline hardness/HRA & $92-93$ & $83-85$ & $91-92$ & $90-92$ \\
\hline Bending strength/MPa & $900-1200$ & $250-400$ & $600-800$ & $600-670$ \\
\hline Elastic Modulus/GPa & $300-320$ & $160-200$ & $290-320$ & $271-286$ \\
\hline Apparent porosity $/ \%$ & $<0.1$ & $10-20$ & 0.01 & $<0.2$ \\
\hline $\begin{array}{l}\text { Coefficient of thermal } \\
\text { expansion } / \times 10^{-6}\end{array}$ & 2.6 & 3.2 & 3.4 & $3.55-3.6$ \\
\hline $\begin{array}{l}\text { Thermal conductivi- } \\
\text { ty } / \mathrm{W} \cdot \mathrm{m}^{-1} \cdot \mathrm{K}^{-1}\end{array}$ & 30 & 17 & $20-25$ & -- \\
\hline
\end{tabular}

the $\mathrm{hBN}$ join, on one hand, $\mathrm{hBN}$ hinders the growth of $\mathrm{Si}_{3} \mathrm{~N}_{4}$ grain, refines the grain; on the other hand, $\mathrm{hBN}$ reduces the grain boundary bonding strength of ceramic composite, and affects its mechanical performance.

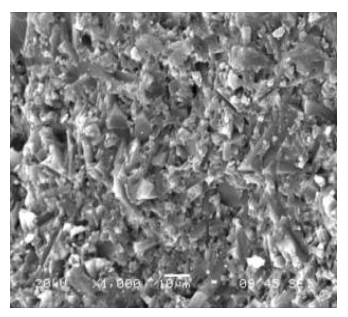

(a) $\mathrm{Si}_{3} \mathrm{~N}_{4}$

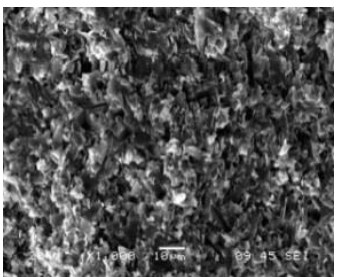

(c) $\mathrm{Si}_{3} \mathrm{~N}_{4}-20 \% \mathrm{hBN}$

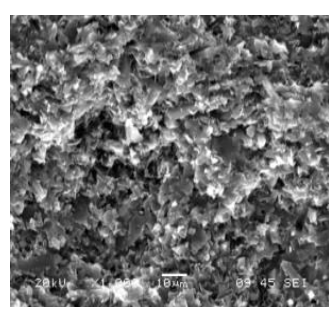

(b) $\mathrm{Si}_{3} \mathrm{~N}_{4}-10 \% \mathrm{hBN}$

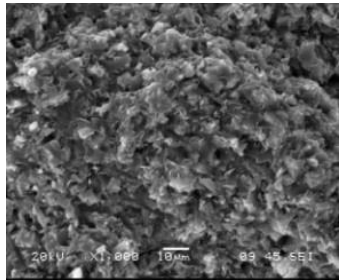

(d) $\mathrm{Si}_{3} \mathrm{~N}_{4}-30 \% \mathrm{hBN}$
Figure 4. Fracture morphology of $\mathrm{Si}_{3} \mathrm{~N}_{4^{-}} \mathrm{hBN}$ ceramic composite

\subsection{Physical and mechanical properties}

Table 2 shows the change of the physical properties of the $\mathrm{Si}_{3} \mathrm{~N}_{4}$ composite ceramic after adding different $\mathrm{hBN}$. The table denotes that, as the hBN content increases, the density and vickers hardness of sample are gradually decreasing; while porosity is gradually increasing, the physical properties of ceramic materials are gradually reducing.

As shown in Figure 5, mechanical properties of $\mathrm{Si}_{3} \mathrm{~N}_{4}-\mathrm{hBN}$ ceramic composite are significantly changed with the content of hBN. Bending strength and fracture toughness are increased with the decreasing volume fraction of $\mathrm{hBN}$. The bending strength of pure $\mathrm{Si}_{3} \mathrm{~N}_{4}$ is reduced from $812 \mathrm{MPa}$ to $465 \mathrm{MPa}$ of $\mathrm{Si}_{3} \mathrm{~N}_{4}-30 \% \mathrm{hBN}$. And the fracture toughness of pure $\mathrm{Si}_{3} \mathrm{~N}_{4}$ is reduced from $8.01 \mathrm{MPa} \cdot \mathrm{m}^{1 / 2}$ to $5.50 \mathrm{MPa} \cdot \mathrm{m}^{1 / 2}$ of the $\mathrm{Si}_{3} \mathrm{~N}_{4}-30 \%$ hBN. 


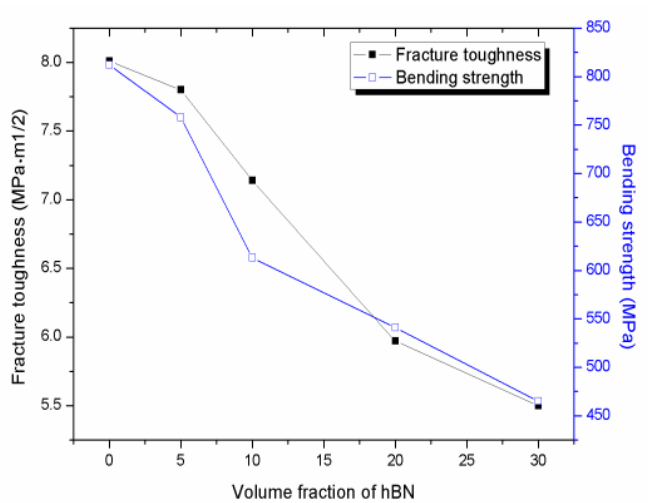

Figure 5. Physical and mechanical properties of $\mathrm{Si}_{3} \mathrm{~N}_{4}-\mathrm{hBN}$ ceramic composite

According to above analysis, it can be concluded that hBN does not improve the physical and mechanical properties of $\mathrm{Si}_{3} \mathrm{~N}_{4}$ ceramics when heat-pressing sintering. Consulting relevant literature, the strength of $\mathrm{Si}_{3} \mathrm{~N}_{4}$ ceramic is closely related to the size, morphology, and distribution of $\beta-\mathrm{Si}_{3} \mathrm{~N}_{4}$ grain. The study of Heinrich ${ }^{[11]}$ shows that the material strength and the grain size have following equation:

$\sigma_{f}=($ cons $\tan t)\left(a / d^{1 / 2}\right)$

Among them, " $a$ " is the length to diameter ratio of $\beta-\mathrm{Si}_{3} \mathrm{~N}_{4}$, " $d$ " is the diameter. Rod-like $\beta-\mathrm{Si}_{3} \mathrm{~N}_{4}$ grain constitutes the mixed microstructure, suppresses the trend of crack propagation, and helps to improve the strength of materials. From material fracture morphology SEM in Figure 4, it can be seen that the grain size will be smaller with the increase of the hBN content. According to the formula (6), it is concluded that the strength of the pure $\mathrm{Si}_{3} \mathrm{~N}_{4}$ value should be higher than $\mathrm{Si}_{3} \mathrm{~N}_{4}-\mathrm{hBN}$ composite ceramic, which is corresponded to the experimental results. In the diagram, $\beta-\mathrm{Si}_{3} \mathrm{~N}_{4}$ grain in pure $\mathrm{Si}_{3} \mathrm{~N}_{4}$ is mixed and disorderly distributed, it shows the crisscross network structure in space, prompts the crack deflected in three-dimensional directions. Its mechanical performance is better than $\mathrm{Si}_{3} \mathrm{~N}_{4}-\mathrm{hBN}$ composite ceramic. In addition, ceramic material will produce $\mathrm{hBN}$ cluster with the hBN join in, it's easy to cause stress concentration and brittle failure in this area which result in a decline in bending strength. These are the reasons that the mechanical performance of pure $\mathrm{Si}_{3} \mathrm{~N}_{4}$ is better than $\mathrm{Si}_{3} \mathrm{~N}_{4}-\mathrm{hBN}$.

Compared the mechanical properties with the $\mathrm{Si}_{3} \mathrm{~N}_{4}$ made by heat-pressing sintering, reaction sintering, pressureless sintering, and post-sintering, the result is shown in Table 3. This table shows that the comprehensive mechanical performance of the heat-pressing sintering $\mathrm{Si}_{3} \mathrm{~N}_{4}$ is more superior than other sintering methods ${ }^{[12-18]}$. This is because the covalent bond polarity of $\mathrm{Si}_{3} \mathrm{~N}_{4}$ is very strong, the diffusion coefficient is very small. It's hard to achieve densification in the general sintering process. But the sintering temperature is higher and the sintering time is longer in heat-pressing sintering process, which makes the $\beta-\mathrm{Si}_{3} \mathrm{~N}_{4}$ grain can grow up and achieve densification. At the same time, the heat-pressing sintering process uses $\mathrm{Y}_{2} \mathrm{O}_{3}$ and $\mathrm{Al}_{2} \mathrm{O}_{3}$ as additive ${ }^{[15]}, \mathrm{Y}, \mathrm{Al}, \mathrm{Si}, \mathrm{O}$, and $\mathrm{N}$ complex liquid phase will be generated in the sintering, they melt $\mathrm{Si}_{3} \mathrm{~N}_{4}$ grain at about $1550{ }^{\circ} \mathrm{C}$ and fill between the grains. With the aid of the surface tension, grains are rearranged, the bulk density is increased, while porosity is decreased. With the increasing temperature, the liquid viscosity is decreased, the dissolving-precipitation process is significant, and the $\alpha-\mathrm{Si}_{3} \mathrm{~N}_{4}$ phase is translated into $\beta-\mathrm{Si}_{3} \mathrm{~N}_{4}$ phase and keeps heat for a period of time which makes it changed completely. At the same time, grain growth, and $\beta-\mathrm{Si}_{3} \mathrm{~N}_{4}$ phase grain are formed into intertwined structure as $\beta-\mathrm{Si}_{3} \mathrm{~N}_{4}$ phase growth which improves the mechanical properties of $\mathrm{Si}_{3} \mathrm{~N}_{4}$ ceramic.

\section{CONCLUSION}

(1) Based on the hot pressing sintering process, addition of hBN into $\mathrm{Si}_{3} \mathrm{~N}_{4}$ inhibits the growth of the crystal grain and makes the ceramic materials generating hBN segregation zone in materials internal, which causes the addition of hBN cannot effectively improve the physical mechanical properties just because of serious stress concentrates and fatigue break down. The hBN has not made effects on improving the physical mechanical properties.

(2) Compared with other sintering process, the physical and mechanical properties of $\mathrm{Si}_{3} \mathrm{~N}_{4}$ prepared by hot-pressing sintering are better than other methods. Improvement of sintering temperature and time can refine the crystal grain and be helpful densification. The changed $\beta-\mathrm{Si}_{3} \mathrm{~N}_{4}$ grain completely forms an intertwined structure and increases the physical and mechanical properties of $\mathrm{Si}_{3} \mathrm{~N}_{4}$. Meanwhile, $\mathrm{Y}_{2} \mathrm{O}_{3}$ and $\mathrm{Al}_{2} \mathrm{O}_{3}$ additives are melted and filled into $\mathrm{Si}_{3} \mathrm{~N}_{4}$ particles at high temperature, leading to a significant drop of the porosity and the increase of density.

\section{ACKNOWLEDGEMENT}

This paper is sponsored by National Natural Science Foundation of China (GN: 51405278), Shaanxi Provincial Department of Education special research projects (14JK1082) and Shaanxi University of Science and Technology Scientific Research Foundation to introduce Dr. (BJ11-01)

\section{REFERENCES}

[1] Zhang Weiru, Wang Chonghai, Liu Jian, Gao Fang Fan \& Jinglin. 2003. Study on High Properties and Micro- 
wave-Transmitting Si3N4-BN Based Ceramic Composites. Bulletin of the Chinese Ceramic Society, 22(3): 1.

[2] Saito T, Imada Y. \& Honda F. 1999. Chemical influence on wear of Si3N4 and hBN in water. Wear, 236(1-2): 153-158.

[3] Liu H. \& Hsu S M. 1996. Fracture behavior of multilayer silicon nitride/boron nitride ceramics. J. $\mathrm{Am} . \mathrm{Ce}$ ram. Soc., 79(9): 2452-2457.

[4] Yu Juanli, Wang Hongjie. \& Zhang Jian. 2009. Effects of Sintering Temperature on Microstructure and Performances of Micro-Porous Si3N4Ceramics. Aerospace Materials \& Technology, 39(5): 48-51.

[5] Camargo S S, Gomes J R. \& Carrapichano J M, et al 2005. Silicon-incorporated diamond-like coatings for Si3N4 mechanical seals. Thin Solid Films, 482(1-2): 221-225.

[6] Carrasquero E, Bellosi A. \& Staia M H. 2005. Characterization and wear behavior of modified silicon nitride. Int. J. Refract. Met. Hard Mater, 23(4-6): 391-397.

[7] Ziegter A, Idrobo J C. \& Cilibulk M K, et al. 2004. Interface structure and atomic bonding characteristics in silicon nitride ceramics. Science, 306(5702): 1768-1770.

[8] Samanta S K, et al.1980. Method of using Si3N4 system for machining Castiron: US, 4227842. 10-14.

[9] Zhu Hailing, Chen Shaou, Li Da. \& Shao Weiquan. 2006. Measuring method for the density and the pore ratio of ceramic materials. Physical Testing and Chemical Analysis Part A: Physical Testing, 42(6): 289-291.

[10]Bindal C. \& Hikmet Üçisik A. 1999. Characterization of borides formed on impurity-controlled chromium-based low alloy steels. Surf. Coat. Technol, 122(2-3): 208-213.

[11] Juergen Heinrich et al. 1988. J Am Ceram Soc, 71(1): 28

[12] Chen xiangiian. 2012. Study on Preparation and Properties of Si3N4 Matrix Ceramics, Central South University.

[13]Cai Shengyou, Li Jinlin. \& Xie Zhipeng. 1999. Influence of interfacial bonding of si3n4 laminated composites on the mechanical properties. Acta Materiae Compositae Sinica. 16(2): 110-115.

[14]WANG Siqing, ZHANG Changrui. \& WANG Shenwei. 2006. Preparation and Mechanic Properties of Si3N4 Matrix Ceramics. Materials Review, 20(z1): 459-461.

[15]Huang Xingping, Li Mo. \& Lv Baojun. 2004. Effects of Y2O3-A12O3 on Mechanical Properties and Microstructure of Hot-press Sinteried Si3N4/ (W, Ti)C Ceramic Composite Materials. Materials for Mechanical Engineering, 28(8): 15-17. 